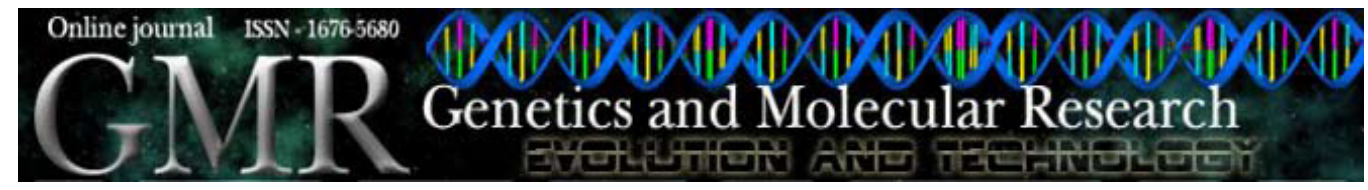

\title{
Genotypic stability and adaptability in tropical maize based on AMMI and GGE biplot analysis
}

\author{
M. Balestre ${ }^{1}$, R.G. Von Pinho ${ }^{2}$, J.C. Souza ${ }^{1}$ and R.L. Oliveira ${ }^{1}$ \\ ${ }^{1}$ Departamento de Biologia, Universidade Federal de Lavras, Lavras, MG, Brasil \\ ${ }^{2}$ Departamento de Agricultura, Universidade Federal de Lavras, Lavras MG, Brasil \\ Corresponding author: M. Balestre \\ E-mail: marciobalestre@hotmail.com
}

Genet. Mol. Res. 8 (4): 1311-1322 (2009)

Received July 13, 2009

Accepted August 7, 2009

Published November 3, 2009

\begin{abstract}
We evaluated the phenotypic and genotypic stability and adaptability of hybrids using the additive main effect and multiplicative interaction (AMMI) and genotype $\mathrm{x}$ genotype-environment interaction (GGE) biplot models. Starting with 10 singlecross hybrids, a complete diallel was done, resulting in 45 doublecross hybrids that were appraised in 15 locations in Southeast, Center-West and Northeast Brazil. In most cases, when the effects were considered as random (only $\mathrm{G}$ effects or $\mathrm{G}$ and GE simultaneously) in AMMI and GGE analysis, the distances between predicted values and observed values were smaller than for AMMI and GGE biplot phenotypic means; the best linear unbiased predictors of $G$ and GE generally showed more accurate predictions in AMMI and GGE analysis. We found the GGE biplot method to be superior to the AMMI 1 graph, due to more retention of $\mathrm{GE}$ and $\mathrm{G}+\mathrm{GE}$ in the graph analysis. However, based on cross-validation results, the GGE biplot was less accurate than the AMMI 1 graph, inferring that the quantity of GE or G + GE retained in the graph analysis alone is not a good parameter for choice of stabilities and adaptabilities when comparing AMMI and GGE analyses.
\end{abstract}

Key words: AMMI; GGE biplot; BLUP; Cross-validation 


\section{INTRODUCTION}

In maize breeding programs, the search for genotypes with high grain yield adapted in the most varied environments is one of the most important objectives for breeders. For that, the choice of populations that show good genetic homeostasis is essential for yield increases.

According to Cruz and Carneiro (2003), some points are indispensable for the choice of genitors such as performance per se of the genitor, high combining ability, low inbreeding (if the objective is inbred line extraction), and genitors with broad adaptability.

When imprecise analysis of the genotype x environment interaction (GE) is performed, several problems arise, mainly the reduction in the accuracy of genotype selection (Lavoranti, 2003). Among the consequences of the G x E interaction are the increase in the phenotypic standard deviation and reduction of the inheritability, and therefore, a decrease in the genetic gain (Matheson and Raymond, 1986).

The measures of GE is extremely important, because it can be used to establish the breeding objectives, such as the choice of genitors, identification of the ideal test conditions and recommendations for regional adapted cultivars (Yan et al., 2000).

Among the statistical analyses proposed for the interpretation of the GE based on the use of biplots, the AMMI (additive main effect and multiplicative interaction) model stands out due to the largest group of technical interpretations available (Duarte and Vencovsky, 1999). AMMI analysis interprets the effect of the genotype $(\mathrm{G})$ and sites (E) as additive effects plus the GE as a multiplicative component and submits it to principal component analysis. Its biplot was identified as GE biplot by Yan et al. (2000).

Yan et al. (2000) proposed a modification of the conventional AMMI analysis called GGE (genotype and genotype-environment interaction) that has been used for GE analysis. The GGE analysis pools genotype effect $(\mathrm{G})$ with $\mathrm{GE}$ (multiplicative effect) and submits these effects to principal component analysis. According to Yan et al. (2000), this biplot is identified as a GGE biplot. The GGE biplot has been recognized as an innovative methodology in biplot graphic analysis to be applied in plant breeding.

In the last years, the AMMI and GGE analyses were debated in relation to graph accuracy. Gauch et al. (2008) questioned GGE analysis about the proportion of G + GE retained in the biplot. In other words, these authors claimed that GGE biplot always explained less G + GE than did the AMMI 2 mega-environment analysis, and sometimes, when GGE2 is buried in noise, the GGE biplot is even less accurate than AMMI 1 analysis. On the other hand, Yan et al. (2007) stated that GGE2 always explained more $\mathrm{G}+\mathrm{GE}$ than AMMI 1 display resulting in a larger graph accuracy. In addition, GGE2 is a direct biplot product, while the AMMI 2 mega-environment analysis cannot be considered a true biplot because it makes use of a predicted table for "which-won-where" pattern discovery.

In spite of the vast number of methods proposed to evaluate stability and adaptability, they are based on phenotypic analyses, considering the treatments and/or progeny as a fixed effect of the model. However, when the objective is the choice of genitors based on progeny performance, the breeding values can be predicted through mixed models and not just estimated based on phenotypic means (White and Hodge, 1989). Smith et al. (2001a) stated that when genotypes and environments are assumed as random and fixed effects, respectively, in mixed models analysis, more realistic results are obtained.

In mixed model context, few alternatives for stability and adaptability study have been available. Van Eeuwijk et al. (1995) suggested the singular value decomposition analysis of GE as random 
effects in the AMMI approach. Similarly, Smith et al. (2001b) and Resende and Thompson (2003) presented the factor analytic multiplicative mixed model for GE analysis considering $\mathrm{G}$ and GE as random effects. However, in the GGE biplot method, G + GE mixed model studies are still scarce.

Therefore, our objective was to evaluate hybrid adaptability and stability through the AMMI and GGE biplot methods, plus the implications of considering G and GE as fixed or random effects in graph accuracy.

\section{MATERIAL AND METHODS}

Ten single-cross hybrids (genotypes coded as 1 to 10) were used. Starting with these hybrids, a complete diallel was performed to obtain 45 double-cross hybrids (11 to 55), which were assessed simultaneously with their parental in a randomized complete block design with three repetitions. The treatments were assessed in 15 environments distributed in the States of Minas Gerais (MG), Bahia (BA) and Goiás (GO) (Table 1), which correspond to the Southeast, Northeast and Center-West areas of Brazil. The plots were made up of two 4-m rows, using a population density of 55,000 plants per hectare.

\begin{tabular}{|c|c|c|c|c|c|}
\hline Environment & Code & Municipality & Latitude & Longitude & Altitude (m) \\
\hline 1 & $\mathrm{~S} 1$ & UFLA, Lavras, MG & $21^{\circ} 13^{\prime} \mathrm{S}$ & $44^{\circ} 58^{\prime} \mathrm{W}$ & 910 \\
\hline 2 & $\mathrm{~S} 2$ & Guarda-Mor, MG & $17^{\circ} 34^{\prime} \mathrm{S}$ & $47^{\circ} 08^{\prime} \mathrm{W}$ & 1010 \\
\hline 3 & $\mathrm{~S} 3$ & Barreiras, BA & $12^{\circ} 08^{\prime} \mathrm{S}$ & $45^{\circ} 00^{\prime} \mathrm{W}$ & 452 \\
\hline 4 & S4 & Jussara, GO & $23^{\circ} 35^{\prime} \mathrm{S}$ & $52^{\circ} 28^{\prime} \mathrm{W}$ & 250 \\
\hline 5 & S5 & Faz. Vitorinha, Lavras, MG & $21^{\circ} 12^{\prime} \mathrm{S}$ & $44^{\circ} 58^{\prime} \mathrm{W}$ & 951 \\
\hline 6 & S6 & São Gotardo, MG & $19^{\circ} 18^{\prime} \mathrm{S}$ & $46^{\circ} 03^{\prime} \mathrm{W}$ & 1058 \\
\hline 7 & S7 & Ijaci, MG & $21^{\circ} 09^{\prime} \mathrm{S}$ & $44^{\circ} 56^{\prime} \mathrm{W}$ & 859 \\
\hline 8 & S8 & Ijaci, $\mathrm{MG}^{*}$ & $21^{\circ} 09^{\prime} \mathrm{S}$ & $44^{\circ} 56^{\prime} \mathrm{W}$ & 859 \\
\hline 9 & S9 & Faz. Mato Dentro, Lavras, MG & $21^{\circ} 13^{\prime} \mathrm{S}$ & $45^{\circ} 03^{\prime} \mathrm{W}$ & 918 \\
\hline 10 & S10 & Ribeirão Vermelho, MG & $21^{\circ} 10^{\prime} \mathrm{S}$ & $45^{\circ} 04^{\prime} \mathrm{W}$ & 884 \\
\hline 11 & S11 & Candeias, $\mathrm{MG}$ & $20^{\circ} 46^{\prime} \mathrm{S}$ & $45^{\circ} 19^{\prime} \mathrm{W}$ & 967 \\
\hline 12 & $\mathrm{~S} 12$ & Paracatu, MG & $17^{\circ} 13^{\prime} \mathrm{S}$ & $46^{\circ} 39^{\prime} \mathrm{W}$ & 580 \\
\hline 13 & $\mathrm{~S} 13$ & Carrancas, $\mathrm{MG}$ & $21^{\circ} 24^{\prime} \mathrm{S}$ & $44^{\circ} 38^{\prime} \mathrm{W}$ & 1005 \\
\hline 14 & S14 & Itutinga, MG & $21^{\circ} 23^{\prime} \mathrm{S}$ & $44^{\circ} 06^{\prime} \mathrm{W}$ & 958 \\
\hline 15 & S15 & Ingaí, MG & $21^{\circ} 22^{\prime} \mathrm{S}$ & $44^{\circ} 45^{\prime} \mathrm{W}$ & 980 \\
\hline
\end{tabular}

To compare the difference between the study of phenotypic and genotypic stability, AMMI analysis via the SAS computational package version 8.0 (SAS Institute, 2000) was used, considering the following model:

$$
Y_{i j}=\mu+G_{i}+E_{j}+\sum_{k=1}^{n} \lambda_{k} \gamma_{i k} \alpha_{j k}+\rho_{i j}+\varepsilon_{i j}
$$

in which: $Y_{i j}$ is the average response of genotype $i$ in environment $j, \mu$ is the general mean, $G_{i}$ is the genotype effect, $\mathrm{E}_{j}$ is the environment effect, $G E_{i j}$ was modeled by $\sum_{k=1}^{n} \lambda_{k} \gamma_{k} \alpha_{\gamma_{k}}+\rho_{y}+\varepsilon_{y j}$ in which: $\lambda_{k}$ is the square root of the $k^{\text {th }}$ eigenvalue of the matrices $(G E)(G E)^{\prime}$ and (GE)'(GE) (from nonnull equal eigenvalues), $\gamma_{i k}$ is the $i^{\text {th }}$ element (related to genotype $i$ ) of the $k^{\text {th }}$ auto vector of $(G E)$ $(G E)^{\prime}, \alpha_{j k}$ is the $j^{\text {th }}$ element (related to environment $j$ ) of the $k^{\text {th }}$ auto vector of (GE)'(GE), $\rho_{i j}$ is the residual not explained by principal components used, and $\varepsilon_{i j}$ is the associated error. The results 
of the AMMI analysis were represented in the form of a graph called a biplot (Gabriel, 1971).

With the objective of verifying the efficiency of the GGE biplot in adaptability and stability graph analysis (Yan et al., 2000), the GGE analysis was carried out utilizing the SAS computational package version 8.0 (SAS Institute, 2000), considering a simplified model for the two main components:

$$
Y_{i j}-y_{. j}=\lambda_{1} \xi_{i 1} \eta_{j 1}+\lambda_{2} \xi_{i 2} \eta_{j 2}+\varepsilon_{i j}
$$

(Equation 2)

in which: $Y_{i j}$ is the yield mean of cultivar $i$ in environments $j, y_{j}$ is the average of environment $j, \lambda_{1} \xi_{i 1} \eta_{j 1}$ is the first principal component (PC 1), $\lambda_{2} \xi_{i 2} \eta_{j 2}$ is the second principal component (PC 2), $\lambda_{1}$ and $\lambda_{2}$ are eigenvalues associated with PC 1 and $\mathrm{PC} 2, \xi_{i 1}$ and $\xi_{i 2}$ are PC 1 and PC 2 scores for genotype, $\eta_{j 1}$ and $\eta_{j 2}$ are the PC 1 and PC 2 environment scores, and $\varepsilon_{i j}$ is the error associated with the model.

Two situations were considered to obtain the stability and genotypic adaptability by AMMI and GGE biplot. In the first situation, just the genotypic means (best linear unbiased prediction, BLUPs) for each site were obtained, i.e., solely genotype effects $(G)$ were considered as random effect (genotype adjustment for block effects within environments) and GE obtained starting from:

$$
G E=Y_{i j}-\bar{Y}_{i .}-\bar{Y}_{. j}-\bar{Y}_{. .}
$$

(Equation 3)

where: $Y_{i j}$ is the genotypic mean (BLUP) of the cultivar $i$ in the environment $j, \bar{Y}_{i}$ is the general genotypic mean of the cultivar $i, \bar{Y}_{j}$ is the general mean of the environment $j$, and $\bar{Y}$.. is the overall mean. Thus, G and GE were taken as random and fixed effects, respectively. In GGE analysis, the genotype effect $(\mathrm{G})$ was included with GE.

In the second case, both $\mathrm{G}$ and GE were analyzed as random effects. Therefore, BLUPs were obtained of the genotypes and genotype-by-environments.

The data were analyzed using the SAS Proc Mixed (SAS Institute, 2000) obtaining BLUP for genotypes and $\mathrm{G} x \mathrm{E}$ interaction, and the best linear unbiased estimator for the fixed effects (overall mean and site effect) using the following linear model:

$$
Y=X \beta+Z g+W i+\varepsilon
$$

(Equation 4)

in which: $Y$ is the observation vector, $\beta$ is the fixed effects vector (block within environments), $g$ is the genotypic effect vector (assumed as random), $i$ is the genotype-by-environment (random) interaction vector, and $\varepsilon$ is the residual vector. $\mathrm{X}, \mathrm{Z}$ and $\mathrm{W}$ are incidence matrices.

The joint solution for the fixed and random effects was obtained by the system of equations according to Henderson (1984):

$$
\left[\begin{array}{l}
\beta \\
g \\
i
\end{array}\right]=\left[\begin{array}{ccc}
X^{\prime} X & X^{\prime} Z & X^{\prime} W \\
Z^{\prime} X & Z Z+I^{-1} \gamma_{1} & Z^{\prime} W \\
W^{\prime} X & W^{\prime} Z & W^{\prime} W+I^{-1} \gamma_{2}
\end{array}\right]^{-1}\left[\begin{array}{c}
X^{\prime} y \\
Z^{\prime} y \\
W^{\prime} y
\end{array}\right]
$$

(Equation 5)

in which

$$
\gamma_{1}=\frac{\sigma_{e}^{2}}{\sigma_{g}^{2}} \text { and } \gamma_{2}=\frac{\sigma_{e}^{2}}{\sigma_{i}^{2}}
$$

(Equation 6) 
The estimates of the residual component, genotypic and GE variances were obtained through restricted maximum likelihood using an iterative process based on the expectationmaximization algorithm.

Using the previously described model, the genotypic values free from interaction were obtained from $(\hat{\mu}+\hat{g})$ where: $\hat{\mu}$ is the mean of all the sites and $\hat{g}_{i}$ is the genotypic effect free from genotype $\mathrm{x}$ environment interaction.

The prediction of genotypic values capitalizing on the interaction mean $\left(\mathrm{ge}_{\mathrm{m}}\right)$ in the different sites is given by $\hat{\mu}+\hat{g_{i}}+\hat{g} e_{m}$.

The phenotypic stabilities and adaptabilities were compared with genotypic effects by cross-validation, namely using accuracy of predictions by AMMI and GGE biplot. Thus, the PRESS (Gabriel, 2002) statistic was applied to measure the discrepancy of the actual $\left(x_{i j}\right)$ and predicted values $\left(\hat{x}_{i j}^{m}\right)$ as

$$
\operatorname{PRESS}(m)=\frac{1}{g e} \sum_{i=1}^{g} \sum_{j=1}^{e}\left(\hat{x}_{i j}^{m}-x_{i j}\right)^{2}
$$

(Equation 7)

Likewise, the correlation parameter among observed and predicted values (PRECOR) was applied to measure the accuracy of the predictions.

\section{RESULTS}

The results of the AMMI analysis are presented in Table 2. It is noted that the PC 1 (AMMI 1) captured $26.36 \%$ of the interaction G x E, while the PC 2 (AMMI 2) captured $16.42 \%$, accumulating $42.77 \%$ in the first two principal components.

\begin{tabular}{|c|c|c|c|c|}
\hline & $\mathrm{SS}_{\mathrm{GE}}$ & $\begin{array}{l}\text { Proportion (GE) } \\
\text { accumulated \% }\end{array}$ & $\mathrm{SS}_{\mathrm{G}}$ & $\begin{array}{c}\text { Proportion G + GE } \\
\text { accumulated } \%\end{array}$ \\
\hline \multicolumn{5}{|l|}{$\overline{\text { AMMI } 1}$} \\
\hline Main effect & - & - & 977.252 & - \\
\hline PCA2 & 524.282 & 26.36 & - & 50.61 \\
\hline \multicolumn{5}{|l|}{ AMMI 2} \\
\hline PCA1 & 524.282 & - & - & - \\
\hline PCA2 & 326.523 & 42.77 & - & - \\
\hline \multicolumn{5}{|l|}{ GGE biplot } \\
\hline PCA1 & 157.542 & - & 943.900 & - \\
\hline PCA2 & 479.841 & 32.05 & 14.970 & 53.82 \\
\hline \multicolumn{5}{|l|}{ AMMI $1 *$} \\
\hline Main effect & - & - & 387.530 & - \\
\hline PCA2 & 310.746 & 35.43 & - & 55.19 \\
\hline \multicolumn{5}{|l|}{ AMMI $2 *$} \\
\hline PCA1 & 310.746 & - & - & - \\
\hline PCA2 & 178.824 & 55.82 & - & - \\
\hline \multicolumn{5}{|l|}{ GGE biplot* } \\
\hline PCA1 & 179.116 & - & 359.630 & - \\
\hline PCA2 & 272.181 & 51.46 & 14.840 & 65.30 \\
\hline \multicolumn{5}{|l|}{ AMMI $1^{+}$} \\
\hline Main effect & - & - & 877.03 & - \\
\hline PCA2 & 131.122 & 26.86 & - & 73.85 \\
\hline \multicolumn{5}{|l|}{ AMMI $2^{+}$} \\
\hline PCA1 & 131.122 & - & - & - \\
\hline PCA2 & 80.680 & 43.39 & - & - \\
\hline \multicolumn{5}{|l|}{ GGE biplot $^{+}$} \\
\hline PCA1 & 28.730 & - & 875.276 & - \\
\hline PCA2 & 155.033 & 31.8 & 0.877 & 77.60 \\
\hline
\end{tabular}

${ }^{*} \mathrm{G}$ as random effect and $\mathrm{GE}$ as fixed effect. ${ }^{+} \mathrm{G}$ and $\mathrm{GE}$ as random effects. 
The AMMI biplot can be visualized in Figure 1. For the biplot analysis, it was shown that the Jussara (S4) and Fazenda Mato Dentro (S9) environments were those that contributed less to GE. On the other hand, UFLA (S1) and Ijaci (S7) were the environments, which contributed more to the $\mathrm{G} \times \mathrm{E}$ interaction.

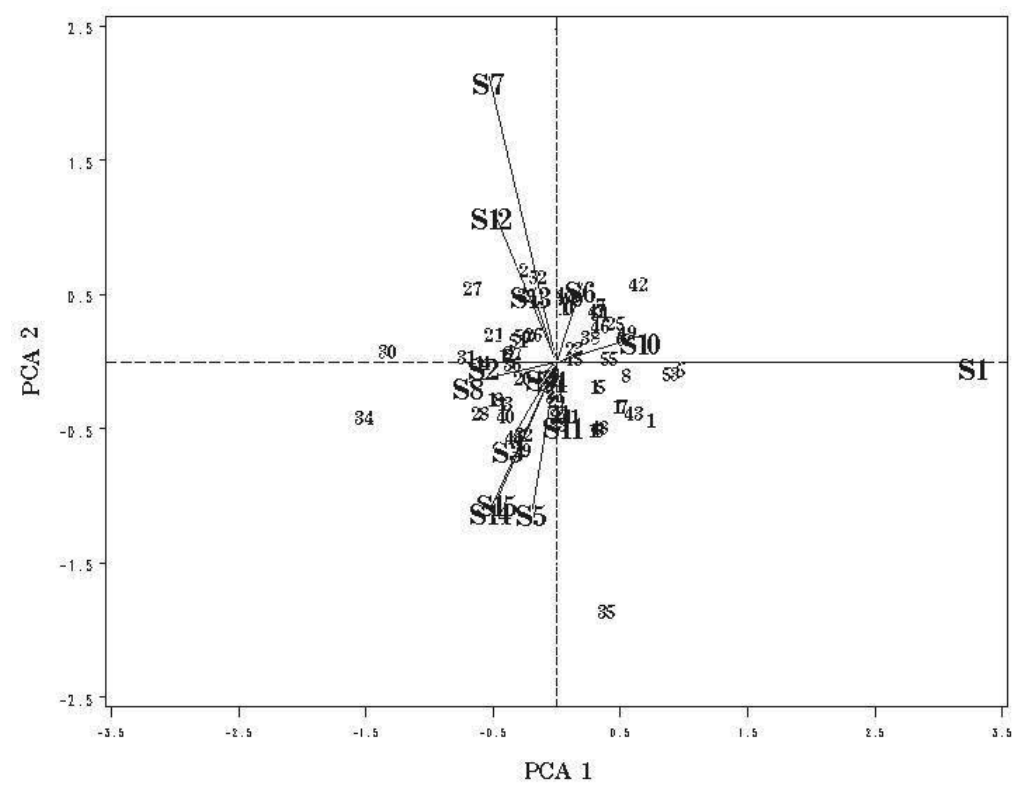

Figure 1. Biplot of the additive main effect and multiplicative interaction (AMMI) analysis based on the phenotypic means of 55 maize genotypes evaluated in 15 environments in the 2005/2006 harvest year. $\mathrm{PC}=$ principal component.

In the same way, it can be inferred that the most stable genotypes were $5 \times 10$ (45), $2 \times 6$ (23) and 3 (A 2555). On the other hand, genotypes 3 x 6 (30), 3 x 10 (34) and 4 x 5 (35) demonstrated greater phenotypic deviation, i.e., contributed more to the genotype-by-environment interaction.

The results of the eigenvalues obtained by the GGE biplot method can be observed in Table 2. The first principal component captured $37.79 \%$ of the sum of the square of genotype $(\mathrm{G})+$ genotype-by-environment (GE), and the second $16.51 \%$, with an accumulation of $53.82 \%$ in the two principal components (GGE2). In addition, the partition of GGE principal components into $\mathrm{G}$ and GE, demonstrated that PC 1 and PCA 2 together retained 32\% of GE and $98.1 \%$ of $\mathrm{G}$ effects.

In Figure 2, three possible mega-environments can be observed. Genotypes 6, 2 and 1 were border genotypes of the three mega-environments. In the first mega-environments delimited by genotype 2, are the sites S2, S7, S8, and S12, the environments S7 and S8 being the Ijaci summer crop and winter crop, respectively. The third mega-environment was delimited by the genotype 1 , where the UFLA environment is situated. The other environments were restricted to the second mega-environment bordered by genotype 6 , which is the winner genotype in those environment groups. 


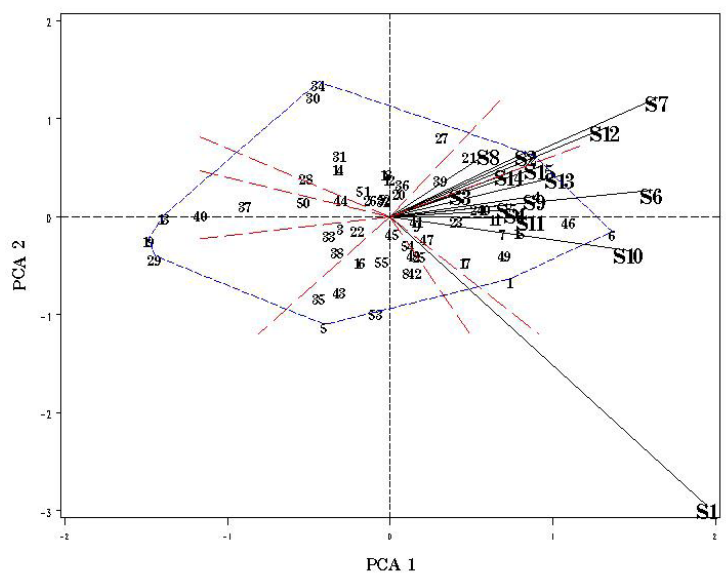

Figure 2. Genotype and genotype-environment interaction (GGE) biplot analysis based on the phenotypic means of 55 maize genotypes evaluated in 15 environments in the 2005/2006 harvest year. $\mathrm{PC}=$ principal component.

Genotype 6 showed the highest general adaptability followed by genotype $46>4=2$. This result can be observed directly in Figure 3 by the genotypes with high values in relation to "average mean coordination" (Yan et al., 2007). Concerning the stability, genotypes 24, 41 and 19 were the ones that showed the least distances in relation to "average mean coordination" characterizing these genotypes as more stable.

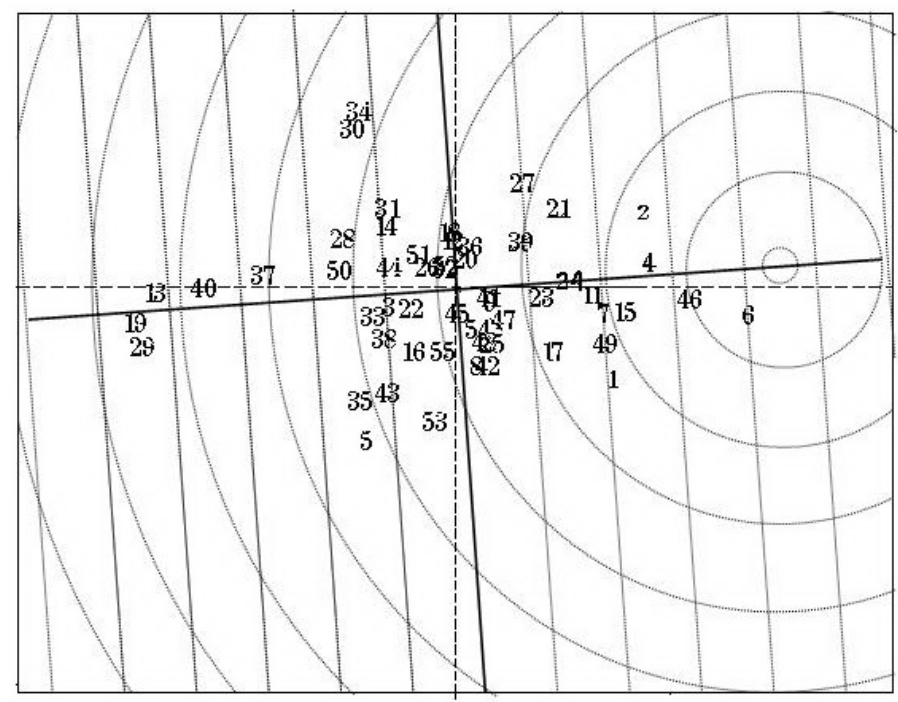

Figure 3. Comparison of genotypes in relation to the 'ideal' genotype for grain yield and stability of 55 maize genotypes evaluated in 15 environments in the 2005/2006 harvest year. 
GGE graphic analysis allows the selection of genotypes simultaneously for adaptability and stability through the genotype distance regarding the "ideal" genotype. The genotypes that fit in those conditions are $6>46>4=2$ (Figure 3). It should be emphasized that although genotype 6 demonstrated good stability and adaptability in the graphic analysis, it had only the 22 nd best stability value.

The ideal environments for the test would be those with high genotype discrimination capacity and located on the AEC abscissa (more representative of the general mean of the environments). Therefore, São Gotardo (S6) and Ribeirão Vermelho (S10) would be ideal test environments (Figure 2).

The predicted genotypic values $\left(\hat{\mu}+\hat{g}_{i}\right)$ for the environment mean representing the 15 sites are given in Table 3. Of the five higher values, two refer to the double-cross hybrids $6 \mathrm{x}$ 7 (46) and $1 \times 6$ (15), suggesting that the parental 6 shows a good potential as genitor, mainly when combining with parental 7. Based on the prediction values for these hybrids, it is possible to suggest the possibility of sowing their progeny outside of the appraised experimental network, since the hybrids were ordered based on the genotypic values free from genotype-byenvironment interaction (Bastos et al., 2007).

\begin{tabular}{|c|c|c|c|c|c|}
\hline Genotype & $\mu+g$ & $\mu+g+g e$ & Genotype & $\mu+g$ & $\mu+g+g e$ \\
\hline 6 & 9.097 & 9.268 & 12 & 8.176 & 8.183 \\
\hline 46 & 8.863 & 9.008 & 8 & 8.174 & 8.175 \\
\hline 4 & 8.869 & 8.975 & 32 & 8.149 & 8.156 \\
\hline 2 & 8.713 & 8.847 & 51 & 8.096 & 8.076 \\
\hline 15 & 8.670 & 8.764 & 26 & 8.076 & 8.050 \\
\hline 7 & 8.685 & 8.761 & 31 & 8.050 & 8.028 \\
\hline 1 & 8.650 & 8.719 & 16 & 8.051 & 8.023 \\
\hline 49 & 8.625 & 8.712 & 3 & 8.037 & 8.017 \\
\hline 10 & 8.635 & 8.708 & 34 & 8.009 & 7.990 \\
\hline 11 & 8.645 & 8.707 & 22 & 8.022 & 7.979 \\
\hline 21 & 8.633 & 8.697 & 55 & 8.000 & 7.978 \\
\hline 24 & 8.597 & 8.622 & 53 & 8.015 & 7.977 \\
\hline 23 & 8.469 & 8.524 & 14 & 8.000 & 7.972 \\
\hline 17 & 8.420 & 8.467 & 44 & 7.966 & 7.935 \\
\hline 27 & 8.398 & 8.454 & 30 & 7.967 & 7.934 \\
\hline & 8.390 & 8.432 & 38 & 7.954 & 7.897 \\
\hline 36 & $\begin{array}{l}8.0356 \\
8.356\end{array}$ & $\begin{array}{l}0.432 \\
8.385\end{array}$ & 35 & 7.917 & 7.889 \\
\hline 20 & 8.302 & 8.324 & 43 & 7.902 & 7.843 \\
\hline 41 & 8.257 & 8.281 & 28 & 7.882 & 7.837 \\
\hline 47 & 8.263 & 8.276 & 33 & 7.884 & 7.829 \\
\hline 42 & 8.259 & 8.255 & 5 & 7.777 & 7.700 \\
\hline 54 & 8.249 & 8.247 & 50 & 7.772 & 7.690 \\
\hline 18 & 8.187 & 8.239 & 37 & 7.603 & 7.475 \\
\hline 48 & 8.220 & 8.234 & 40 & 7.446 & 7.297 \\
\hline 52 & 8.234 & 8.226 & 13 & 7.282 & 7.158 \\
\hline 45 & 8.212 & 8.211 & 19 & 7.230 & 7.068 \\
\hline 9 & 8.262 & 8.206 & 29 & 7.206 & 7.009 \\
\hline 25 & 8.210 & 8.199 & & & \\
\hline
\end{tabular}

$\mu=$ grand general mean; $g=$ predicted genotypic value; $g e=$ genotypic values capitalizing on the average interaction.

Table 3 presents the estimates of the genetic values capitalizing on the genotype-byenvironment interaction. In this case, the attributed values are valid just for the areas of the group of experiments or in areas with equivalent pattern of genotype-by-environment interaction (Table 3). It is noted that, for the superior genotypes, the genotypic values capitalizing on the interaction are equal to the genotypic values without the GE capitalization.

The genotypic values predicted for each environment were submitted to GGE and 
AMMI analysis, obtaining genotypic adaptability and stability. In this case, it can be observed in Table 2 that the PC explained $65.30 \%$ of the G + GE by GGE biplot analysis, and $55.82 \%$ of the GE for AMMI 2 analysis. Otherwise, when $\mathrm{G}$ and GE were assumed as random effects, the GGE biplot retained in the two PC 77.6\% of G + GE, and the AMMI $243.39 \%$ of GE.

In most cases, when the effects were considered as random (only $\mathrm{G}$ effects or $\mathrm{G}$ and GE simultaneously), the distances among predicted values and observed values were smaller than AMMI and GGE biplot phenotypic means (Figure 4). However, for the GGE biplot approach, it can be seen that when $G$ was assumed as random effects and GE as fixed effects (GGE2*), the predictions showed a larger distance in relation to the observed values (Figure 4).

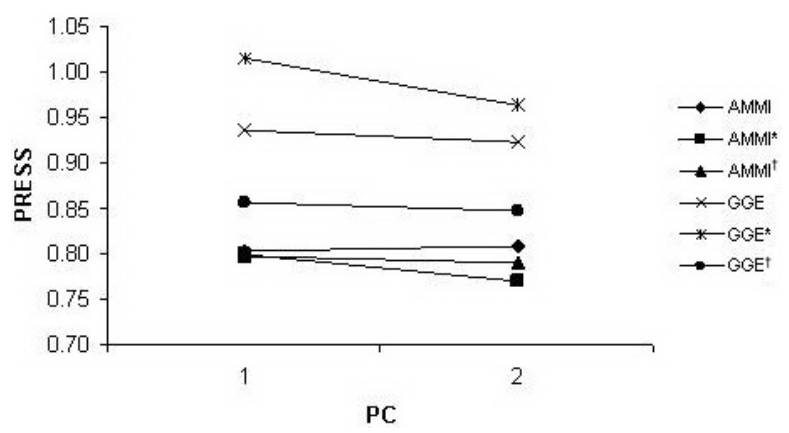

Figure 4. PRESS values for additive main effect and multiplicative interaction (AMMI) and genotype and genotype-environment interaction (GGE) biplot analysis taking into account two principal components (PC). See legend to Table 2 for AMMI and GGE explanations.

The BLUPs of G and GE generally showed more accurate predictions in AMMI and GGE analysis (Figure 5). The AMMI phenotypic means demonstrated slight correlation inferiority among the predicted values and actual phenotypic means in relation to AMMI's BLUP, i.e., $\mathrm{G}$ and $\mathrm{GE}$ as random and fixed effects, respectively (AMMI*), and $\mathrm{G}$ and $\mathrm{GE}$ as random effects $\left(\mathrm{AMMI}^{\dagger}\right)$. On the other hand, GGE* was less accurate than GGE phenotypic means, demonstrating that considering genotypes as random effects and GE as fixed effects in GGE analysis can lead to loss in accuracy.

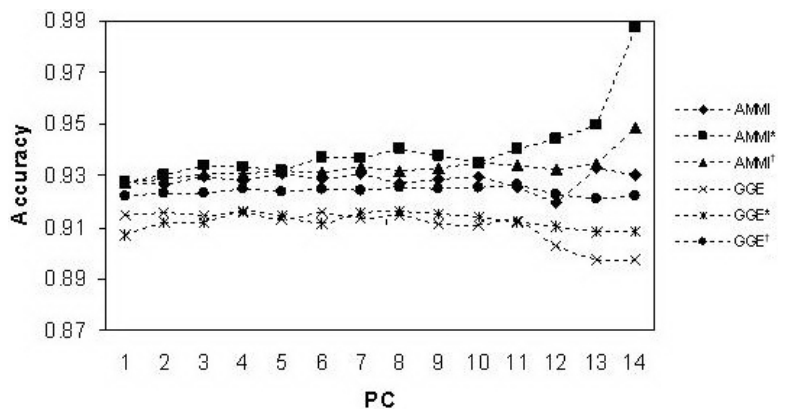

Figure 5. Correlation among observed and predicted values by additive main effect and multiplicative interaction (AMMI) and genotype and genotype-environment interaction (GGE) biplot by cross-validation approach. See legend to Table 2 for AMMI and GGE explanations. $\mathrm{PC}=$ principal component. 
In all situations, the GGE biplot was less accurate than AMMI analysis, and that fact can point out that the largest retention of GE or G $+\mathrm{GE}$ in the graph analysis is not always a sign of more accuracy. This was also evident because GGE* was less accurate than the GGE phenotypic mean, although it retained more GE and more G + GE in the biplot.

\section{DISCUSSION}

In recent years, several methodologies have been proposed with the intention of describing in an easy and precise manner the performance of genotypes in diverse environments. More recently, the AMMI methodology has been questioned as to its efficiency in explaining the genotype-by-environment interaction and mega-environment pattern (Yan et al., 2007). On the other hand, in a more recent review, Gauch Jr. et al. (2008) question GGE analysis for counting genotypes in the multiplicative effect, and they conclude that AMMI 1 and AMMI 2 analysis is always superior to GGE biplot analysis, mostly when GGE2 is buried in noise.

Ebdon and Gauch (2002), Gauch Jr. (2006) and Gauch Jr. et al. (2008) claimed that mega-environment classification based on AMMI 1 analysis should be the equivalent as that based on the GGE biplot. In addition, these authors argued that in AMMI 2 mega-environment analysis it is also possible to visualize "which-won-where" and mega-environment pattern, with the advantage of always retaining more in G + GE than in GGE2 analysis.

Therefore, the AMMI 1 display, AMMI 2 mega-environments and GGE2 were compared, in the first instance, in relation to their capacities to retain $\mathrm{G}+\mathrm{GE}$ in graph analysis (Yan et al., 2007; Gauch Jr. et al., 2008).

Based on the results obtained in this study, it is observed that the GGE biplot method was superior to the AMMI 1 graph due to more retention of GE and G + GE in graph analysis (Table 2). In other words, considering the arguments of Yan et al. (2007), the GGE biplot should be more accurate than the AMMI 1 display. However, Figure 5 reveals the opposite results. That is, the GGE biplot with two PC was less predictive than AMMI 1, except for GGE2 ${ }^{+}$, which shows accuracy values very close to those of AMMI 1. This finding disagrees with Dias and Krzanowski (2003) who did not observe differences in accuracy gain between AMMI and GGE2.

Similarly, to infer that the GGE graph is more accurate than AMMI 1, it is necessary to bear in mind the cross-validation approach because larger GE or G + GE retained in graph does not always result in more accuracy. That is, our results reveal that more G $+\mathrm{GE}$ or GE retained in graph analysis to compare AMMI and GGE approaches is not an appropriate parameter in choosing the better method.

Gauch Jr. et al. (2008) pointed out that in some cases, the results achieved in this study could occur because GGE biplot can retain more noise than pattern, and when that occurs, according to these authors, the AMMI 1 and AMMI 2 should be the more accurate predictive models, as also observed in the present study. However, in another study conducted by Balestre et al. (2009), the rule AMMI $1<$ GGE2 < AMMI 2 stated by Gauch Jr. et al. (2008) was observed by cross-validation analysis, but this cannot always be pragmatic.

In AMMI analysis, considering $\mathrm{G}$ or $\mathrm{G}+\mathrm{GE}$ as random effects generally leads to a slightly superior accuracy, not showing great alterations in graph analysis. However, in GGE biplot the BLUPs of the genotypes and genotype-by-environment effects $\left(\mathrm{GGE}^{\dagger}\right)$ lead to greater accuracy, producing an important difference in relation to GGE2 phenotypic means and being the principal one detected in Figure 6, where just one mega-environment is evident instead of 
three as in GGE2. Although the dataset presented in this study is limited due to the number of genotypes, sites and one harvest year, the GGE2 ${ }^{\dagger}$ power mega-environment detection and accuracy compared to GGE2 could have a great influence in the cultivar test due to the decrease in appraisal costs and chance of wrong recommendations, respectively. Thus, it is evident that in most cases, considering $\mathrm{G}$ and $\mathrm{GE}$ as random effects leads to more reliable results because these effects are adjusted by intra-class correlation, or specifically by the heritability of G and GE.

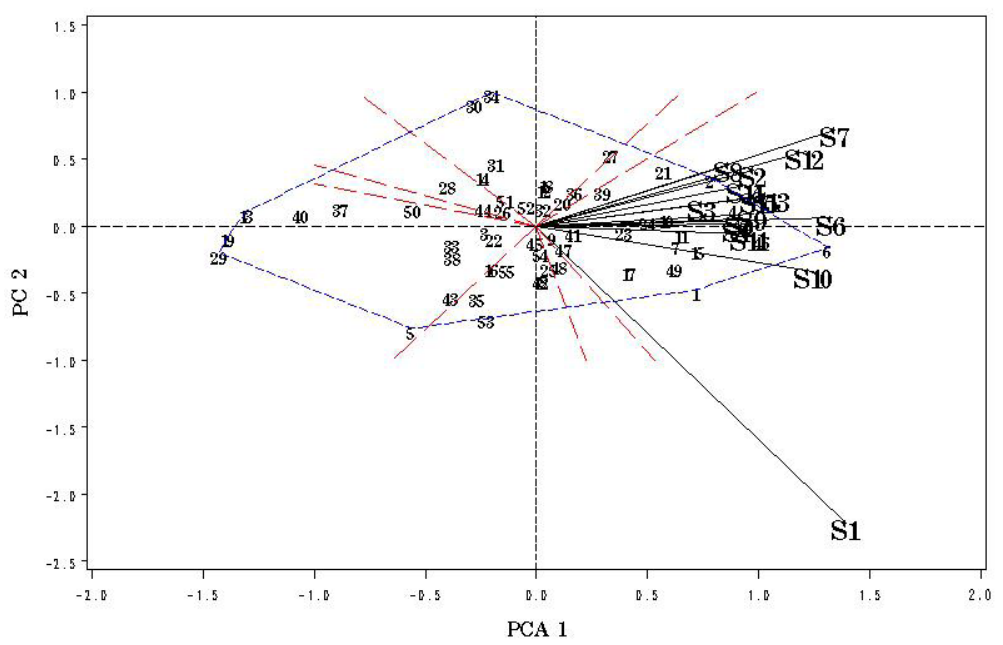

Figure 6. Genotype and genotype-environment interaction (GGE) biplot analysis based on 55 maize genotypes evaluated in 15 environments in the 2005/2006 harvest year with G and GE effects considered as random effects (BLUPs of genotypes and genotypes-by-environments).

Based on our results, it can be concluded that the AMMI 1 and AMMI 2 methods can be more accurate than GGE biplot even when retaining a lower proportion of GE or G + GE, inferring that the quantity of GE or G + GE retained in the graph analysis by itself, is not a reasonable parameter in the choice of stabilities and adaptabilities between AMMI and GGE approach.

Also, there is evidence that GGE and AMMI phenotypic means demonstrate a decrease in accuracy in relation to GGE and AMMI evaluated by BLUP approach, mainly in GGE biplot analysis, where the G + GE effects are subject to principal components analysis simultaneously.

\section{ACKNOWLEDGMENTS}

Research supported by CAPES.

\section{REFERENCES}

Balestre M, Souza JC, Von Pinho RG, Oliveira RL, et al. (2009). Yield stability and adaptability of maize hybrids based on GGE biplot analysis characteristics. Crop Breed. Applied Biotechnol. 9: 226-234. 
Bastos IT, Barbosa MHP, Resende MDV, Peternelli LA, et al. (2007). Evaluation of genotype versus environment interaction in sugarcane using mixed models. Pesq. Agropec. Trop. 37: 195-203.

Cruz CD and Carneiro PCS (2003). Modelos Biométricos Aplicados ao Melhoramento Genético. Editora UFV (Universidade Federal de Viçosa), Viçosa.

Dias CTS and Krzanowski WJ (2003). Model selection and cross validation in additive main effect and multiplicative interaction models. Crop Sci. 43: 865-873.

Duarte JB and Vencovsky R (1999). Interação Genótipos x Ambientes. Uma Introdução à Análise AMMI. ESALQ/USP, Ribeirão Preto.

Ebdon JS and Gauch HG (2002). Additive main effect and multiplicative interaction analysis of national turfgrass performance trials. Crop Sci. 42: 489-496.

Gabriel KR (1971). The biplot graphic display of matrices with application to principal component analysis. Biometrika 58: 453-467.

Gabriel KR (2002). Le biplot: Outil d'exploration de données multidimensionnelles [Biplot - tool for exploration of multidimensional data]. J. Soc. Fr. Stat. 143: 5-55.

Gauch HG Jr (2006). Statistical analysis of yield trials by AMMI and GGE. Crop Sci. 46: 1488-1500.

Gauch HG Jr, Piepho HP and Annicchiarico P (2008). Statistical analysis of yield trials by AMMI and GGE: further considerations. Crop Sci. 48: 866-889.

Henderson CR (1984). Applications of Linear Models in Animal Breeding. University Guelph, Guelph.

Lavoranti OJ (2003). Estabilidade e Adaptabilidade Fenotípica Através da Re-amostragem “Bootstrap" no Modelo AMMI. Doctoral thesis, Escola Superior de Agricultura Luiz de Queiroz, Piracicaba.

Matheson AC and Raymond CA (1986). A review of provenance $\mathrm{x}$ environment interaction. Its practical importance and use with particular reference to the tropics. Commonw. Forest. Rev. 65: 283-302.

Resende MDV and Thompson R (2003). Multivariate Spatial Analysis of Multiple Experiments and Longitudinal Data. Embrapa Florestas, Colombo.

SAS Institute (2000). SAS/STAT User's Guide. Version 8. SAS Institute Inc., Cary.

Smith A, Cullis B and Gilmour A (2001a). The analysis of crop variety evaluation data in Australia. Austr. N. Z. J. Stat. 43: $129-145$

Smith A, Cullis B and Thompson R (2001b). Analyzing variety by environment data using multiplicative mixed models and adjustments for spatial field trend. Biometrics 57: 1138-1147.

Van Eeuwijk FA, Keizeir LCP and Bakker JJ (1995). Linear and bilinear models for the analysis of multi-environment trials. II: An application to data from the Dutch Maize Variety Trials. Euphytica 84: 9-22.

White TL and Hodge GR (1989). Predicting Breeding Values with Applications in Forest Tree Improvement. Kluwer Academic, Dordrecht.

Yan W, Hunt LA, Sheng Q and Szlavnics Z (2000). Cultivar evaluation and mega-environment investigation based on the GGE biplot. Crop Sci. 40: 597-605.

Yan W, Kang MS, Ma B, Woods S, et al. (2007). GGE biplot vs. AMMI analysis of genotype-by-environment data. Crop Sci. 47: 643-653. 